\title{
GESTÃO E DEMOCRACIA NA ESCOLA: LIMITES E DESAFIOS \\ http://dx.doi.org/10.5902/2176217113789
}

\author{
Neide Pena Cária \\ Universidade do Vale do Sapucaí, Brasil. \\ Mileide Pereira Santos \\ Universidade do Vale do Sapucaí, Brasil.
}

\begin{abstract}
Resumo
O presente artigo aborda a evolução do princípio da democracia na história da educação pública brasileira, a fim de contextualizar o processo de gestão democrática, atualmente em evidência na escola pública, como condição para a melhoria da qualidade da educação. O objetivo é analisar, a partir da Constituição Federal de 1988 e da Lei de Diretrizes e Bases da Educação Nacional de 1996, quais os princípios de uma gestão democrática, com vistas a compreender os limites e os desafios da democracia no âmbito escolar. Tem-se como pressuposto orientador deste artigo que a participação dos atores da escola e da comunidade escolar constitui-se em um fator determinante para que haja a gestão democrática. O conceito de participação foi abordado na perspectiva de Diaz Bordenave (1994), que a considera como um aprendizado. Como metodologia, utilizou-se da pesquisa documental e bibliográfica. O estudo apresenta uma crítica ao modelo de gestão que se diz democrática, mas que não abre espaço para a participação dos atores da escola. Evidencia que a participação efetiva dos professores e da comunidade nos processos de gestão escolar ainda é um devir, um grande desafio e um dos entraves à implantação da democracia na escola. Nesse processo, o gestor se destaca como líder e responsável pelo rompimento do paradigma tradicional da gestão conservadora da escola.

Palavras-chave: gestão democrática, participação, qualidade da educação.
\end{abstract}

\section{MANAGEMENT AND DEMOCRACY IN SCHOOL: LIMITS AND CHALLENGES}

\begin{abstract}
This article discusses the evolution of the principle of democracy in the history of public education in Brazil in order to contextualize the process of democratic management, currently in evidence in the public school as a condition for improving the quality of education. It has been analysed as a goal what are the principles of democratic management, the Federal Constitution of 1988 and the Law of Guidelines and Bases of National Education, 1996, $\mathrm{n}^{\circ}$. 9394, seeking to understand the limit of the sense of democracy in schools and its challenges. The guiding assumption of this article is that the participation of the school actors and the school community is the main factor for the initial democratic management. The concept of participation was approached from the
\end{abstract}


perspective of Diaz Bordenave (1994) that considers participation as a learning experience. The methodology used was a survey documents and bibliographic, with qualitative approach. The study shows a critical management model that says itself democratic, but there is no room for the participation of school actors. Shows that the effective participation of teachers and the community is still a becoming, a great challenge and one of the barriers to the implementation of democracy in school. The figure of the manager was highlighted as a leader and responsible for the disruption of the traditional paradigm of conservative management of the school.

Key-words: democratic management, participation, educational quality. 


\section{Introdução}

debate sobre o princípio da gestão democrática na educação pública nacional se instalou, de forma mais efetiva, a partir da promulgação da Constituição Federal de 1988 e da consequente Lei de Diretrizes e Bases da Educação Nacional. Desde então, a questão da gestão democrática da escola tornou-se objeto de estudo e discussão nos ambientes acadêmicos, na mídia e em eventos, sendo apropriado muito mais por profissionais de outras áreas do que da área educacional. Busca-se debater e propor novos modos de gestão como condição para atingir a efetiva qualidade da educação, principalmente a educação básica pública, visando romper com o paradigma tradicional da administração escolar e instalar novas estratégias que contemplem a participação de todos os atores da escola e da comunidade escolar no trabalho pedagógico da escola. Entretanto, o que se tem observado na experiência docente, no cotidiano da escola, é que os pais e os alunos não participam dessa discussão e, muitas vezes, os professores ficam alijados de um processo do qual são personagens principais.

Neste artigo o conceito de gestão democrática, que permeia as reflexões, parte de Veiga (1995, p. 18), o qual afirma que para "que a ação administrativa democrática aconteça é necessária a ampla participação dos representantes dos diferentes segmentos da escola nas decisões e nações administrativas e pedagógicas ali envolvidas", ou seja, os alunos e pais devem estar envolvidos no processo de gestão da escola para que haja a gestão democrática. Nesse sentido, utiliza-se o conceito de participação de Diaz Bordenave (1994), segundo o qual há forças atuantes na dinâmica do processo participativo e, apesar da participação ser uma necessidade básica, o homem não nasce sabendo participar: "A participação é uma habilidade que se aprende e se aperfeiçoa. Isto é, as diversas forças e operações que constituem a dinâmica da participação devem ser compreendidas e dominadas pelas pessoas" (Bordenave, 1994, p. 47).

Diante do exposto, este artigo tem como objetivo analisar, por meio da pesquisa documental, os princípios de uma gestão democrática, a partir dos documentos oficiais como a Constituição Federal de 1988, a Lei de Diretrizes e Bases da Educação Nacional, o Estatuto da Criança e do Adolescente e o projeto político-pedagógico da escola, a fim de compreender o limite do sentido de democracia no âmbito escolar.

A escolha do tema e as análises efetuadas se respaldam nos documentos oficiais que subsidiaram este estudo, articulados à experiência docente em uma instituição pública municipal de educação básica numa cidade do Sul de Minas Gerais.

\section{O contexto da gestão democrática}

A gestão democrática na educação pode ser interpretada a partir da chegada dos portugueses na colônia e a forma como aconteceu o início da educação no Brasil, em que os primeiros habitantes desta terra que viria, mais tarde, a se chamar Brasil, tiveram seus costumes e valores abafados e, porque não dizer, negados de forma arbitrária. Num sucinto retorno à história da educação brasileira, é possível observar que o aspecto democrático nas políticas educacionais nunca existiu.

Os portugueses desembarcaram no Brasil em 1500 e perceberam que, nas tribos indígenas, os responsáveis em transmitir os ensinamentos da sua cultura era a própria família e o índio mais velho da tribo, conhecido como cacique. Os jesuítas vieram em 
seguida, 1549, com o intuito de pregar a religião católica e alfabetizar os índios com essa doutrina. Sem respeitar os seus costumes e a sua cultura, o ensino era realizado nas ocas, consideradas as primeiras escolas do Brasil (Romanelli, 1987).

Em 1759, Marques de Pombal, que governava Portugal nessa época, expulsou os Jesuítas do Brasil e, pela primeira vez, a educação na colônia passou a ser de responsabilidade do Estado. Desde então, a educação no Brasil sempre esteve dividida entre quem tinha mais recursos econômicos e os que nada tinham, independentemente da categorização pública ou privada.

Proclamada a Independência do Brasil, em 1822, a educação ocupou um lugar importante, fato que se consolidou com a primeira Constituição, outorgada em 1824, tornando a instrução primária gratuita para todo cidadão perante a lei. Com a Proclamação da República, em 1889, mais uma vez tornou-se necessário reavaliar a educação no país, sendo um período marcado por diversas reformas na educação.

$\mathrm{Na}$ estrutura educacional brasileira, até 1930, não existia uma política nacional de educação que prescrevesse diretrizes gerais e a elas subordinassem os sistemas de ensino. Uma das primeiras medidas do governo provisório, instalado com a Revolução de 1930, foi a criação do Ministério da Educação e Saúde Pública, conferindo à União o poder para exercer sua tutela sobre os vários domínios do ensino no país. A realidade naquele momento exigia mão de obra especializada para as indústrias e era necessário investir na educação (Shiroma, 2000).

Em 1937 é outorgada uma nova Constituição, enfatizando o ensino profissionalizante no artigo 129:

A infância e à juventude, a que faltarem os recursos necessários à
educação em instituições particulares, é dever da Nação, dos Estados e
dos Municípios assegurar, pela fundação de instituições públicas de ensino
em todos os seus graus, a possibilidade de receber uma educação
adequada às suas faculdades, aptidões e tendências vocacionais. [...] O
ensino pré-vocacional profissional destinado às classes menos favorecidas
é em matéria de educação o primeiro dever de Estado. Cumpre-lhe dar
execução a esse dever, fundando institutos de ensino profissional e
subsidiando os de iniciativa dos Estados, dos Municípios e dos indivíduos
ou associações particulares e profissionais.

O ano de 1964 foi marcado pelo golpe militar e no início da década de 1970 foi instituída a Lei de Diretrizes e Bases da Educação Nacional, lei n. 5.692. Com o fim do regime militar aprovou-se uma nova Constituição, que cita a gestão democrática na escola no artigo 206: "O ensino será ministrado com base nos seguintes princípios: VI gestão democrática do ensino público, na forma da lei”.

Desde a promulgação da Constituição Federal de 1988, os sistemas de ensino passaram a se organizar de modo compartilhado entre a União, os Estados, o Distrito Federal e os Municípios em regime de colaboração. Em 1996, com a emenda constitucional n. 14, foi implantado o Fundo de Manutenção e Desenvolvimento do ensino Fundamental e de Valorização do Magistério - Fundef. O Fundef foi, na sequência, regulamentado pela lei n. 9.424, de 24 de dezembro do mesmo ano, e pelo decreto $n$. 2.264, de junho de 1997, sendo implantado nacionalmente em 1ํㅡ de janeiro de 1998, 
quando passou a vigorar a nova sistemática de redistribuição dos recursos destinados ao ensino fundamental.

O processo de municipalização é evidenciado como o veículo de mudança de uma educação de fracasso e de exclusão para uma educação de qualidade, diante da perspectiva de mais participação e controle dos atores da educação, ou seja, uma gestão mais democrática. No art. 206, inciso VI da Constituição Federal, estabelece-se, prescritivamente, o caráter democrático permeia a intenção do Estado ao oficializar que:

O ensino será ministrado com base nos seguintes princípios: I - igualdade de condições para o acesso e permanência na escola; II - liberdade de aprender, ensinar, pesquisar e divulgar o pensamento, a arte e o saber; III - pluralismo de ideias e de concepções pedagógicas, e coexistência de instituições públicas e privadas de ensino; IV - gratuidade do ensino público em estabelecimentos oficiais; $\mathrm{V}$ - valorização dos profissionais da educação escolar, garantidos, na forma da lei, planos de carreira, com ingresso exclusivamente por concurso público de provas e títulos, aos das redes públicas; (Redação dada pela Emenda Constitucional no 53 , de 2006) VI - gestão democrática do ensino público, na forma da lei; VII garantia de padrão de qualidade. VIII - piso salarial profissional nacional para os profissionais da educação escolar pública, nos termos de lei federal. (Incluído pela Emenda Constitucional n. 53, de 2006)

Na Lei de Diretrizes e Bases da Educação Nacional de 1996, art. 14, o caráter democrático é reforçado por meio da gestão democrática:

Art. 14 - Os sistemas de ensino definirão as normas da gestão democrática do ensino púbico na educação básica, de acordo com as suas peculiaridades e conforme os seguintes princípios. I. Participação dos profissionais da educação na elaboração do Projeto pedagógico da escola: II. Participação das comunidades escolar e local em conselhos escolares ou equivalentes.

O princípio da gestão democrática encontra-se reforçado também no Estatuto da Criança e do Adolescente, lei n. 8.069, de 13 de julho de 1990, que assegura, como direito dos pais, a participação na definição das propostas pedagógicas da escola de seus filhos, ter conhecimento do processo pedagógico, acompanhamento de seu desenvolvimento escolar e dos resultados da avaliação, assim como, garante a liberdade de expressão à criança e ao adolescente.

Conforme Cária (2006), embora a gestão democrática não tenha ainda se efetivado de fato, legalmente ela já é uma realidade, faltando apenas ser implantada na prática e no cotidiano da escola. Para isso, o processo de gestão da escola já prevê a participação coletiva em diversos procedimentos formais e regulamentares da escola, como: a elaboração do projeto político pedagógico, os conselhos e colegiados ou equivalentes, que são processos democráticos previstos apenas às escolas públicas, com raras exceções no ensino privado (Cária, 2006).

O conselho escolar é muito importante na gestão democrática, pois é uma ligação da escola com a comunidade e possibilita uma ruptura da gestão verticalizada e autoritária do diretor. O regimento escolar expressa o projeto educativo da escola, por isso deve ser construído coletivamente com a participação de todos os segmentos da 
comunidade escolar, permitindo que a escola expresse sua identidade sem perder de vista a legislação e as diretrizes e políticas educacionais nacionais e estaduais. Vale ressaltar que, na forma da lei, a gestão democrática está limitada ao ensino público, o que conforme Cária (20060,) merece questionamento, uma vez que o princípio democrático é assegurado a todos os cidadãos brasileiros e não apenas àqueles que se formam no ensino público.

O apelo sistemático à adoção de medidas descentralizadores e mais democráticas no campo educacional se intensificou a partir da década de 1990, mais especificamente após a Conferência Mundial de Educação para Todos em Jontiem, Tailândia, que foi financiada pela Unesco, Unicef, Pnud e Banco Mundial. Desse evento participaram representantes de 155 governos que subscreveram a declaração ali aprovada, comprometendo-se a assegurar uma educação básica de qualidade às crianças, jovens e adultos. A partir das prerrogativas dessa conferência, a educação passou a ocupar espaço nas discussões e agenda dos governos, em nível global, o que deu origem a novas conferências e a diversos documentos oficiais contemplando metas para atingir a educação de qualidade. Entre as diversas prerrogativas encontra-se o princípio democrático da gestão escolar.

Os anos 1990 foram também palco de uma ampla reforma do estado nacional, orientada por ideais neoliberalistas e, nessa esteira, vem ocorrendo uma profunda reforma na área educacional para adequar a estrutura educacional brasileira a um processo de reconfiguração do papel do Estado brasileiro. A reforma trouxe uma reformulação no campo educacional: de uma administração burocrática mais centrada numa concepção autoritária para uma administração gerencial. Seu foco se apresenta articulado aos princípios democráticos, mas, ao mesmo tempo, com características de gestão empresarial, baseada na política de responsabilização e na gestão por resultados. Nesse novo modelo de gestão incentivam-se práticas que priorizem, pela via democrática, a efetiva participação política, social, econômica e cultural da comunidade escolar, sendo a municipalização uma das políticas adotadas pelo Estado como forma de transferir a gestão da educação e de seus recursos às comunidades. Com a ampliação da municipalização do ensino fundamental em todo país, a partir de uma retórica que visa a melhorar a qualidade da educação básica, a responsabilidade da educação pública vem sendo transferida aos municípios e, em troca, eles poderão reaver recursos retidos para a manutenção dessa educação.

De acordo com Trojan (2009), a reforma do Estado e a redução dos gastos públicos causaram impactos na gestão do sistema na maioria dos países latino-americanos, destacando-se a municipalização da educação obrigatória, mudanças no modelo de gestão e a instituição de sistemas nacionais de avaliação. Entre os principais objetivos proclamados pelas reformas, em nível internacional, constam a melhoria da eficácia da atividade administrativa, a melhoria da qualidade na prestação dos serviços públicos, o aumento da produtividade na administração do Estado e, especialmente, a redução dos gastos públicos, cujos principais instrumentos utilizados foram a privatização e a descentralização (Souza, 2002), ou seja, podem ser identificados quatro grandes objetivos centrais nas orientações internacionais que balizam as reformas de Estado: a) melhoria da eficácia da atividade administrativa; b) melhoria da qualidade na prestação 
dos serviços públicos; c) diminuição das despesas públicas; d) aumento da produtividade da administração do Estado.

No caso do Brasil, os reflexos dessas orientações podem ser observados no Plano diretor de reforma do aparelho do estado, que tem como um dos princípios fundamentais a mudança no modelo de gestão do Estado e, por consequência, nas políticas públicas, como a gestão da educação. Um dos princípios orientadores do plano é o de que o Estado só deve executar diretamente as tarefas que são exclusivas de Estado, ou que apliquem os recursos do Estado. No conjunto, as estratégias apontadas por esse plano são a privatização, a publicização e a terceirização.

É nesse contexto que se insere o discurso da gestão democrática da educação no Brasil, um espaço tenso e contraditório em que democracia ainda um processo de consolidação, um devir que, diante do plano de reforma do Estado, passa agora a ser reorientada pela nova ordem mundial neoliberalista que tem procurado homogeineizar políticas educacionais.

\section{Gestão participativa na escola}

Conforme Bastos (2003), o primeiro movimento de participação na gestão da escola pública foi o dos estudantes secundaristas no antigo Distrito Federal, durante a gestão de Anísio Teixeira, como secretário da educação (1931-1935), o primeiro a relacionar democracia com a administração da educação.

Colares (2003) também afirma que, a partir do final dos anos 1980, começaram a surgir ideias de que era necessária a participação da comunidade nas discussões dos problemas educacionais e de outras questões que estavam relacionadas ao interesse da comunidade, oportunizando a democracia na escola. Os movimentos reivindicatórios dos professores favoreceram a discussão sobre o modelo burocrático e hierárquico de organização da educação e da escola, propondo a sua superação e a democratização.

Com a globalização e as novas necessidades do mundo, a gestão participativa passou a ser uma das premissas para uma participação popular no sentido de construir uma identidade e autonomia da escola. Conforme Paro (1986), a gestão participativa é construída pelas forças políticas, viabilizando o bem comum no contexto social na qual a escola está inserida, pois a escola e a comunidade estão dialeticamente constituídas. Repensar a teoria e a prática no sentido de adequar alguns controles formais e incentivar a gestão participativa na educação constitui-se em instrumentos de construção de uma nova cidadania:

Tendo em conta que a participação democrática não se dá espontaneamente, sendo antes um processo histórico em construção coletiva coloca-se a necessidade de se preverem mecanismos institucionais que não apenas viabilizem, mas também incentivem práticas participativas dentro da escola pública. (Paro, 1986, p. 46)

Paro (1986) enfatiza que gestão participativa é um processo com resultados em longo prazo, pois é necessária a ruptura de velhos hábitos de uma gestão centralizada no diretor para uma gestão que valorize a participação de todos que fazem parte da escola e de toda a comunidade na qual a escola está inserida. 
Nesse mesmo sentido, Hora (1994) defende que a escola tem de realizar um trabalho com pais, funcionários e alunos para que todos possam compreender que a instituição é um espaço de referencia da comunidade sendo aberta a reuniões e sugestões com os mesmos. Para a autora o planejamento elaborado com a participação de todos é o principal instrumento para desenvolver a gestão participativa:

O principal instrumento da administração participativa é o planejamento participativo, que pressupõe uma deliberada construção do futuro, do qual os diferentes segmentos de uma instituição, cada um com sua ótica, seus valores e seus anseios, que, com poder de decisão, estabelecerão uma política, que deve estar em permanente debate, reflexão, problematização, estudo, aplicação, avaliação e reformulação, em função das próprias mudanças sociais e institucionais. (Hora, 1994, p. 51)

Diante do exposto, o gestor é o responsável em implementar a democracia na escola pública. Ele deve proporcionar a todos os membros envolvidos um ambiente escolar agradável, com a interação de todos na busca da realização de um trabalho pedagógico coletivo, construindo uma identidade própria para a escola com resultados satisfatórios e eficazes em todos os segmentos.

Segundo Luck (1996, p. 37),

o entendimento do conceito de gestão já pressupõe, em si, a idéia de participação, isto é, do trabalho associado de pessoas analisando situações, decidindo sobre seu encaminhamento e agindo sobre elas em conjunto. Isso porque o êxito de uma organização depende da ação construtiva conjunta de seus componentes, pelo trabalho associado, mediante reciprocidade que cria um todo orientado por uma vontade coletiva.

Diante do exposto, entende-se que a gestão participativa ainda é um conceito desconhecido para muitos diretores que desejam continuar seguindo uma linha autoritária, como o único dono do saber e das decisões tomadas na escola. Esta prática não tem mais lugar na sociedade atual, pois, independente da vontade dos gestores, a escola está articulada com a sociedade, segundo os princípios constitucionais democráticos, e não se admite mais uma gestão verticalizada e o alijamento daqueles que são parte constitutiva do processo pedagógico. Sem a participação do aluno e suas famílias e dos professores não há educação e, muito menos de qualidade.

Dados divulgados na mídia tem mostrado que as escolas que têm o nível de aprendizagem mais alto são aquelas onde ocorre a gestão democrática com a participação de todos os funcionários e da comunidade, na qual se encontram inseridas. Os problemas sempre vão existir, afinal a educação trata de relações entre pessoas, com experiências, interesses e expectativas diferentes. Porém, quando o trabalho educativo é realizado com responsabilidade, diálogo e comprometimento, com todos assumindo responsabilidades, o trabalho coletivo torna-se mais produtivo e os problemas podem ser solucionados no coletivo. 


\section{A diferença entre gestão e administração na educação}

De acordo com Martins (1999, p. 165), "administração é o processo racional de organização, comando e controle. $\mathrm{O}$ administrador que estabelece as regras do jogo, e não os membros da unidade, cabendo a estes apenas implementá-las". O sentido de gestão caracteriza-se pelo reconhecimento da importância da participação consciente e esclarecida das pessoas nas decisões sobre a orientação e manejo de seu trabalho. Está associada ao fortalecimento da idéia de democratização do processo pedagógico, entendida como participação de todos nas decisões e em sua efetivação.

Como argumenta o referido autor, na administração tradicional tem-se um líder na qual a ação é mais individual e centralizado. Já o conceito de gestão traz a ideia de uma organização onde cada um é parte do processo da administração e do sistema como um todo. Assim, espera-se que num processo de gestão ocorra um desenvolvimento e aperfeiçoamento de ação coletiva e de espírito de equipe, ou seja, existe uma intenção democrática e espera-se a participação de todos os envolvidos no processo pedagógico.

Nesse sentido, segundo Martins (1999), o diretor tem como papel fundamental liderar o desenvolvimento do processo de superação do sentido administrativo para o de gestão e, para isso, é necessário que esteja consciente desse papel, bem como, estar disposto a atuar em plenitude para conseguir a adesão de todos os demais elementos da escola a uma gestão participativa.

A importância do comprometimento do gestor na gestão democrática é destacada também por Paro (1986, p. 160), que compara o sentido dos dois termos - administração e gestão:

A administração escolar inspirada na cooperação recíproca entre os
homens deve ter como meta a constituição, na escola, de um novo
trabalhador coletivo que, sem os constrangimentos da gerência
capitalista e da parcelarização desumana do trabalho, seja uma
decorrência do trabalho cooperativo de todos os envolvidos no
processo escolar, guiados por uma vontade coletiva, em direção ao
alcance dos objetivos verdadeiramente educacionais da escola.

Pelo exposto, a administração escolar implica uma forma de trabalho verticalizada e hierarquizada. Nesse modelo a maior parte dos funcionários da escola não tem nenhuma relação com o poder de decisão e sugestões, a comunidade, na maioria das vezes, não participa, o diretor tem a sua função específica, sendo o responsável por tudo na escola. $\mathrm{Na}$ gestão escolar a forma de organização é diferente, pois diretores, professores, funcionários no geral, pais e alunos tem a participação considerada fundamental na tomada de decisões, sempre com responsabilidade e respeito por todos.

Entretanto, não basta mudar as palavras ou termos, pois a perspectiva da gestão traz inúmeros elementos relacionados a uma perspectiva gerencial do campo empresarial, muito criticada por diversos pesquisadores, devido à ideia do gerenciamento da educação como serviço e como mercadoria. Portanto, a gestão democrática como política pública apresenta a sua complexidade e não é um processo tão simples como muitas vezes tem sido difundido. 


\section{O outro lado da gestão democrática: implicações e desafios da prática}

De acordo com Hora (1994), no Brasil, a administração escolar esta intrinsecamente relacionada a teorias da administração de empresas, por fazermos parte de uma sociedade capitalista cuja função principal é o lucro e muitos se esquecem do lado social:

O diretor da escola, antes de ser um educador comprometido com a formação do educando, depara-se com situações em que se reduza mero repassador de ordens; burocrata atado atrás das mesas assinando papéis de pouco significado para a educação, "capataz de limpeza e organização" do prédio escolar, sendo obrigados a cumprir programas educacionais que continuadas vezes não levam em conta o conhecimento da realidade $e$ as necessidades daquela comunidade escolar. (Hora, 1990, p. 19)

Entretanto, diretores conscientes e preocupados em promover possibilidades de mudanças e melhorias à comunidade na qual esta inserida podem, apesar do modelo burocrático do sistema de ensino, implantar valores e práticas de participação do grupo ou da equipe de profissionais da escola, valendo-se de brechas que a legislação permite, desde que esteja comprometido com os princípios da democracia e, dessa forma. numa atitude inovadora podem atingir melhores resultados aliando o administrativo ao pedagógico. Nesse sentido, vale retomar que o diretor tem essa possibilidade garantida, principalmente no momento da elaboração do projeto político pedagógico, junto com a equipe de profissionais da escola, levando em consideração a realidade e necessidades da comunidade na qual esta inserida. No entanto, mas muitas vezes o diretor escolar, devido ao seu processo de formação, não sabe como se proceder. Portanto, com as mudanças advindas do novo modelo de administração da educação, agora como gestão, faz-se necessário primeiramente repensar a formação de gestores.

Os procedimentos formais e legais instituídos para implantar a democracia na escola, como os colegiados, o projeto pedagógico, o ECA, o regimento e conselho escolar, são de grande importância no processo de democratização da escola e da educação, mas na prática, nem sempre funcionam como instâncias de discussões e de participação efetiva.

No caso da municipalização, seu efeito para a democratização prática da escola acabou resultando "numa simples transferência de encargos e gastos do Governo central para os Municípios, cujos problemas se acentuaram em face da diversidade de suas condições socioeconômicas" (Krawczyk; Vieira, 2008, p. 53). Mesmo contando com políticas de equalização como o Fundo de Manutenção e Desenvolvimento da Educação Básica e de Valorização do Magistério - Fundeb -, as diferenças persistem de um Estado para outro e de um município para outro, devido às desigualdades sociais e econômicas extremas, em âmbito nacional:

A descentralização do sistema educacional para as diferentes instâncias governamentais, que minimizou a responsabilidade do Estado pela educação, é comum a todos os países. No entanto, observam-se diferenças significativas na regulação desse processo, que vai desde a mera transferência do serviço educacional até a forte regulamentação do financiamento da educação. (Krawczyk; Vieira; 2008, p. 130-131) 
A escola é o lugar de realização e avaliação de seu projeto educativo, uma vez que necessita organizar seu trabalho pedagógico com base em seus alunos. Daí a necessidade do projeto político-pedagógico ser construído e vivenciado por todos os envolvidos com o processo educativo na escola, mas não podemos esquecer que ele tem algumas regras para sua criação e que estas estão articuladas aos interesses dos órgãos do governo e na gestão democrática é necessário aventurar e arriscar para poder criar a sua autonomia.

Como afirma Cária e Garroni (2011), a gestão democrática deve atingir a escola na sua totalidade, não somente na administração. Deve chegar à sala de aula, que é o espaço onde a relação saber, professor e aluno acontece. Dessa forma, a construção do saber e a construção da subjetividade e da educação política tornam-se norteadores de um processo democrático. O projeto pedagógico é o que deve nortear a escola nas suas propostas educacionais, devendo ser voltado para a realidade escolar e em relação com as políticas mais amplas. É, ainda, uma ferramenta por excelência para que o gestor possa se desenvolver na sua prática cotidiana e dar à escola uma dimensão democrática e participativa. Ao abrir espaço para a participação de todos os atores da escola na construção do projeto político pedagógico, o gestor estará contribuindo para a implementação da gestão democrática na escola.

Veiga (1995) reforça a importância do saber construir o projeto político-pedagógico de uma instituição e o saber delimitar os objetivos que se deseja alcançar, a partir de reflexão sempre em conjunto com toda a comunidade escolar. É pela prática que o projeto político-pedagógico é consolidado, por isso, ele deve ter a participação de todos que estão inseridos na escola e na comunidade escolar com muita responsabilidade e compromisso ético e nunca deve perder de foco a identidade da escola.

Sobre participação, Diaz Bordenave (1994, p. 16) afirma que esta

tem duas bases complementares: uma base afetiva - participamos porque sentimos prazer em fazer coisas com os outros - e uma base instrumental participamos porque fazer coisas com os outros é mais eficaz e eficiente que fazê-las sozinhos. [...] Essas duas bases - afetiva e instrumental deveriam equilibrar-se. Porém, às vezes, elas entram em conflito e uma delas passa a sobrepor-se à outra.

No caso do projeto pedagógico, se realizado com a participação afetiva e instrumental dos professores e da comunidade escolar, poderá contribuir para a eficiência e a eficácia da gestão da escola e do trabalho pedagógico por ela realizado, uma vez que a educação é essencialmente um processo humano.

Essa compreensão é reforçada também por Araujo (2009), segundo o qual o projeto pedagógico deve ser discutido e analisado de forma democrática. O planejamento das ações diárias da instituição implica no registro das ações que serão desenvolvidas, de modo organizado, com os devidos responsáveis pelas ações planejadas, o resultado esperado e também a missão, os objetivos, os princípios e diretrizes da instituição, afirma o referido autor. Entretanto, o projeto político-pedagógico não deve ser trancado numa gaveta, como é comum. Ao contrário, ele deve estar acessível a todos, inclusive, nos módulos e reuniões de pais e colegiados, ele deve ser lembrado, analisado e avaliado para que se possa por em prática as propostas contempladas no projeto. 
Entretanto, envolver professores, funcionários da escola e toda a comunidade na construção do projeto político-pedagógico é ainda um desafio nas escolas públicas da educação básica, principalmente no que se refere ao tempo e à disponibilidade dos envolvidos para a participação de encontros e reuniões necessárias para a discussão de propostas de forma democrática e respeitando a todos, apesar de ser o mesmo, praticamente uma exigência legal, desde a promulgação da LDB.

Para Gadotti (2000, p. 56), todo projeto supõe rupturas com o presente e promessas para o futuro:

Projetar significa quebrar um estado confortável para arriscar-se, atravessar um período de instabilidade e buscar uma nova estabilidade em função da promessa que cada projeto contém de estado melhor do que o presente.Um projeto educativo pode ser tomado como promessa frente a determinada ruptura.As promessas tornam visíveis os campos de ação possível, comprometendo seus atores e autores.

O projeto pedagógico é apenas um dos principais instrumentos de construção da prática democrática na escola. Cabe ressaltar a existência dos colegiados, também denominado de Conselho Escolar, que tem a função de decidir ações a serem tomadas na gestão da escola e dos recursos da escola, inclusive avaliar constantemente o projeto pedagógico, em conjunto com os alunos, funcionários, professores, pais, enfim, com a comunidade escolar. Segundo Freire (1998), deve-se fazer tudo o que puder no sentido de incentivar e convocar os que vivem em torno da escola e dentro da escola para a participação na escola.

Não se trata de qualquer tipo de participação. Ao contrário, a participação precisa fazer sentido para o indivíduo - professor, pais, alunos -, para que o seu trabalho seja motivador e para que possam sentir-se pessoalmente responsáveis pelo resultado do seu trabalho, da sua participação e da instituição escolar, como instituição concreta onde a participação se efetiva.

Ou seja, ao fazer algo que sintam significativo, além de receberem feedback sobre aquilo que foi realizado, o profissional da educação e todos atores da escola poderão sentir-se mais valorizados e comprometidos com a gestão da escola e com todo o seu processo pedagógico. Entretanto, a superação do paradigma conservador e tradicional de gestão centralizada e hierarquizada ainda é um dos entraves e também um desafio para a democratização da educação e da própria sociedade.

\section{Considerações finais}

Pelas revisões bibliográficas e da análise documental foi evidenciado que a gestão democrática, como política educacional, não pode ser apenas uma proposta da administração, mas deve atingir toda escola e a comunidade, até chegar à sala de aula. É importante que pais, professores, conselhos, funcionários participem de toda a proposta pedagógica da escola para que ela seja, dentro do possível, democrática e participativa.

O fator participação foi tomado como o principal meio de assegurar a gestão democrática da escola, pois possibilita o conhecimento dos objetivos e metas da escola, o conhecimento da estrutura e da organização da dinâmica escolar, assim como das relações que se estabelecessem dentro da escola e com seu entorno. É neste ambiente 
que se destaca a figura do gestor, como líder e responsável pela construção e condução do trabalho pedagógico da escola de forma democrática e responsável (accountability).

Não é uma missão fácil para o gestor, pois ele é o responsável em conduzir o processo democrático e realizar uma ruptura com a visão autoritária e conservadora histórica na educação brasileira, como foi relatado ao longo deste texto. Os órgãos governamentais instituem propostas e regras por meio de documentos formais, mas ao gestor cabe conhecer a legislação e saber usufruir dos princípios legais para tornar a gestão da escola, na prática, mais democrática.

A gestão democrática é um processo complexo, mas possível, e não passa apenas pela eleição de diretores, mas principalmente pela elaboração do projeto pedagógico, que é o grande articulador do processo democrático da escola, quando o gestor mobiliza a comunidade escolar para que se comprometa e participe dos processos decisórios e pedagógicos da escola.

Entretanto, embora a gestão democrática esteja prevista na Constituição Federal e na Lei de Diretrizes e Bases da Educação Nacional, não há ainda a conscientização dos profissionais da escola, dos pais e da comunidade sobre necessidade de um envolvimento mais efetivo. Em consequência, não acontece a participação dos mesmos em reuniões, debates para a construção do projeto político-pedagógico e nos demais processos decisórios e, nem tão pouco, em discussões para tratar dos problemas inseridos na comunidade escolar que refletem nos resultados do processo de ensinar e de aprender na escola, uma vez que o aluno vai por inteiro para o ambiente escolar, ou seja, o ambiente escolar é metaforicamente a representação da comunidade onde está inserida a escola.

Diante do que procuramos expor, ressaltamos que uma gestão de educação orientada por princípios democráticos participativos no ensino público pode favorecer a melhoria da qualidade da educação. Da mesma forma que a participação é um processo de aprendizagem, o exercício da democracia também é um processo de aprendizagem e podem favorecer a formação de novos sujeitos políticos, imbuídos de valores democráticos que possam ir ao encontro das aspirações populares e das novas exigências de convivência humana na contemporaneidade.

\section{Referências}

ARAUJO, Maria Cristina Munhoz. Gestão escolar. Curitiba: lesde, 2009.

BASTOS, João Batista. Gestão democrática. Rio de Janeiro: DPE, 2003.

BRASIL. Lei 9394/96. Lei de Diretrizes e Bases da Educação Nacional (LDB). Disponível em <http://bd.camara.gov.br/bd/bitstream/handle/bdcamara/2762/ldb_5ed.pdf>. Acesso em: 2 jan., 2013.

BRASIL. Constituição de 1824, 1937 e 1988. Disponível em <http://www.planalto.gov.br/ccivil03constituicao/constituicao>. Acesso em: 30 dez., 2012.

CÁRIA, Neide Pena; GARRONI, Maria de Lourdes. O gestor escolar e a função educativa. http://www.artigonal.com/educacao-artigos/o-gestor-escolar-e-a-funcao-educativa-4993639.html. Acesso em: 15 abr., 2013. 
CÁRIA, Neide Pena. A parceria de empresas educacionais de iniciativa privada com as redes municipais de educação do sul de Minas Gerais. São Paulo: PUCSP, 2012. $232 f$. Tese (doutorado em Educação). Pontifícia Universidade de São Paulo.

COLARES, Anselmo Alencar; SOUZA COLARES, Maria Lília Imbiriba. Do autoritarismo repressivo à construção da democracia participativa: história e gestão educacional. Campinas: Autores Associados, 2003.

DEMO, Pedro. Política social, educação e cidadania. São Paulo: Papirus, 1994.

DIAZ BORDENAVE Juan Henrique. O que é participação. São Paulo: Brasiliense, 1994.

FREIRE, Paulo. Pedagogia da autonomia: saberes necessários à prática educativa. São Paulo: Paz e Terra, 1998.

GADOTTI, Moacir. Autonomia da escola: princípios e propostas. São Paulo: Cortez, 2000.

HORA, Dinair Leal da. Gestão democrática na escola: artes e ofícios da participação coletiva. São Paulo: Papirus, 1994.

KRAWCZYK, Nora Rut; VIEIRA, Vera Lucia. A reforma educacional na América Latina nos anos 1990: uma perspectiva histórico-sociológica. São Paulo: Xamã, 2008.

LIBANIO, José Carlos. Organização e gestão escola: teoria e prática. Goiânia: Alternativa, 2004.

MARTINS, José Padro. Administração escolar. São Paulo: Atlas 1999.

PARO, Vitor Henrique. Administração escolar: introdução crítica. São Paulo: Cortez, 1986.

ROMANELLI, Otaíza de Oliveira. História da educação no Brasil (1930-1973). Petrópolis: Vozes, 1987.

SHIROMA, Eneida Oto; MORAES, Maria Célia M. de; EVANGELISTA, Olinda. Política educacional. Rio de Janeiro: DP\&A, 2000.

SOUZA, Antônio Lisboa Leitão de. Estado e educação pública: tendências administrativas e de gestão. In: OLIVEIRA, Dalila Andrade; ROSAR, Maria de Fátima Félix (orgs.). Política e gestão da educação. Belo Horizonte: Autêntica, 2002, p. 89-103.

TROJAN, Rose Meri. Políticas educacionais na América Latina: tendências em curso. Revista Iberoamericana de Educación. n. 51/1, 2009. Disponível em: http://www.rieoei.org/deloslectores/3172Trojan.pdf. Acesso em: 4 fev., 2013.

VEIGA, IIma Passos. Alencastro (org.). Projeto político-pedagógico da escola: uma construção possível. São Paulo: Papirus, 1995.

Neide Pena Cária é professora no Curso de Mestrado em Educação da Universidade do Vale do Sapucaí, Pouso Alegre/MG; doutora em Educação pela PUCSP. É professora e coordenadora do curso de especialização em Gestão Educacional na Universidade do Vale do Sapucaí.

Endereço: Rua Monsenhor Dutra, 20/502 - 37550-000 - Pouso Alegre - Minas Gerais, Brasil.

E-mail: iinap@uol.com.br. 
Mileide Pereira Santos é professora em instituição pública municipal na cidade de Borda da Mata/MG. É estudante no curso de especialização em Gestão Educacional na Universidade do Vale do Sapucaí.

Endereço: Rua Rio Branco, 113 - 37564-000 - Borda da Mata - MG - Brasil.

E-mail: mileidesantos8@gmail.com.

Recebido em 11 de maio de 2014.

Aceito em 27 de junho de 2014. 